\title{
THE CONNECTIVE TISSUE SEPTA IN THE ADULT HUMAN LUNG *
}

\author{
BY \\ LYNNE REID \\ From the Institute of Diseases of the Chest, Brompton, London
}

(RECEIVED FOR PUBLICATION SEPTEMBER 1, 1958)

The septa of connective tissue which divide the lung have usually been studied because of their relation to secondary lobules or incidentally to investigation of some associated structure, such as lymphatics (Flint, 1906 ; Cunningham, 1916). In the human lung the secondary lobules are defined as the units of respiratory tissue which are enclosed within thin connective tissue septa (Laguesse and d'Hardivillier, 1897 ; Felix, 1928 ; Miller, 1947 ; Loosli and Potter, 1951; Birnbaum, 1954). Laguesse and d'Hardivillier described the septa as subtended from the larger lymphatics which form polyhedral rings on the pleura. Felix went further by comparing secondary lobules in different parts of the lung. $\mathrm{He}$ divided the lobe into cortex (Lappenmantel) and medulla (Lappenkern), the cortex being two lobules deep and separated from the medulla by strong connective tissue passing from medulla to pleura. Because of the detail of his description, in which he represented the septa diagrammatically as complete lines, his work is usually quoted whenever the anatomy of the peripheral part of the lung is discussed. This description of the septa implied that they are present throughout the lung and are complete, and it may be that Felix's technique of injection of the bronchial tree with subsequent corrosion of the lung was in part responsible for his assumption that the septa were fully developed.

Fischer (1953) threw some doubt on this conclusion when he mentioned that the boundaries of the secondary lobules are usually not as clearly defined in the human lung as described by Felix. Later Van Allen and Lindskog (1930) showed that the lobules as described in this way by the anatomist are not self-contained units, since there is collateral drift of air between them. Their recognition of this phenomenon led to renewed study of the alveolar walls in the search for alveolar pores as the

*A communication based on these studies was presented to the Thoracic Society in July, 1956. possible basis, but relatively little curiosity was aroused as to the role of the septa. In an early paper on collateral ventilation Van Allen and Jung (1931) stated that "the interlobular septa are incomplete and the alveoli at the places of fusion of the lobules communicate with each other by minute openings, probably the pores of Kohn."

Still no detailed description has been given of the degree and manner in which the anatomical incompleteness of the septa contributes to collateral ventilation. As it seemed that the arrangement of the septa would be relevant to an understanding not only of the function of the normal lung but also of the morphology and pathogenesis of certain pulmonary diseases a more systematic study of the adult structure was undertaken and is described here. The foetal arrangement has already been described (Reid and Rubino, 1959).

\section{Material and Method of Examination}

Eighteen lungs from 12 subjects (seven male and five female) were used for detailed study (13 lungs were from patients who died from a non-pulmonary cause and five were resection specimens containing a small peripheral carcinoma). With the exception of a child of 6 , the ages ranged from 30 to 63 . In addition, a large number and variety of operation specimens showing such changes as bronchiectasis, of collapse, chronic bronchitis, emphysema, and $N$ pneumonia were studied for corroboration. The $\mathrm{N}$ lungs were fixed by injecting formalin into the $\omega$ trachea. As septa can be identified with the naked eye, their topographical distribution, total number, 0 regional variation, and their relation to veins and other structures were largely studied macroscopically. The lungs were sliced, some vertically, some horizontally, at $0.5 \mathrm{~cm}$. intervals, but incompletely, the slices being left attached at one corner so that they could be turned back like the leaves of a book.

Microscopy was used to confirm deductions from naked-eye examination and to establish histological features. For an appreciation of the relation of the septa to other components of the lung, series of 
sections were essential. Blocks of various sizes, from many regions, were cut in different planes in relation to the pleura, their selection and the method of cutting depending on the particular arrangement of structure to be studied. For example, to relate the pleural pattern of lymphatics to underlying septa, serial sections were cut parallel to the pleura for a distance of several millimetres, while to facilitate study of the arrangement of septa at the tip of the lingula the sections were cut horizontally, at right angles to pleural surfaces and for a distance of $1.5 \mathrm{~cm}$. from the tip.

Sections $7 \mu$ thick were stained with haematoxylineosin or by the Verhoeff-van Gieson method. These were most conveniently studied on the stage of a plate microscope. Line diagrams of septa and bronchioles were drawn on graph paper to give some idea of scale, and photographs of step sections at low magnification $(x 12)$ were used for studying the arrangement.

\section{Structure of Pleural Septa}

The septa usually appear as thin white lines, although, like the fascial planes elsewhere in the body, they may resemble a fissure. Histologically the areolar tissue forming the core of the septa is bounded by a thin layer of elastic fibres common to the pleura and to the underlying alveoli. The external or true elastic layer of the pleura has no connexion with the septa, as it passes parallel to the pleural surface across the base of the septa without dipping into them. Lymphatics and vessels also may pass in these septa, but in any one section are often at the edge of the septum rather than within it. Septa extend into the lung from the surface of the pleura to varying depths, having an irregular free edge deep in the lung, which in cross-section may appear blunt or tapering or, if the septum has bifurcated, as two short prongs. Septa may be divided into two types, the first being shallow with a maximum depth in the adult of only 2 or $3 \mathrm{~mm}$., and the second having a depth of the order of 2 to $3 \mathrm{~cm}$. The shallow septa vary considerably in the length of their attachment to the pleura and often contain a blood vessel or lymphatic at their intrapulmonary edges. By reason of their small size they do little to subdivide the lung, and are therefore of less functional importance than the larger septa. Near the edge of the lung, a septum may pass across to the adjacent layer of pleura, in which case it may have little free edge.

\section{Relationship of Septa to the Mosaic Pattern of Lymphatics on the Pleura}

In the adult lung no constant relationship can be demonstrated between the large septa and the pattern of pleural lymphatics recognized by the naked eye. Over the lateral aspect of the lower lobe, for example, septa are sparse and yet the pattern of lymphatics is visible on the surface. Elsewhere, as over the inferior tip of the lingula, the pattern corresponds more to that of the underlying septa ; but even where there are septa in relation to the pleural pattern they do not form a closed system and are usually less complete than that pattern would suggest. Serial sections cut parallel to the pleura often show that, although immediately subjacent to it a pattern of septa resembling that of the lymphatics may be demonstrated, this is progressively lost, so that sections at a depth of half a centimetre include no septa.

\section{Distribution of THe SePta}

Both macroscopic and microscopic examination show that the most striking feature of the septa in the adult lung is the variation in the number present in different parts (Fig. 1). A detailed account of lobar distribution is included in the description of the septa in the foetal lung (Reid and Rubino, 1959), but in a general way it can be stated that it is only in the subpleural region, to a maximum depth of 2 to $3 \mathrm{~cm}$., that the large septa of connective tissue are present. In the deeper part of the lung areolar tissue as a thin sheath, often continuous with a septum, encloses the bronchi and blood vessels, and this, if cut tangentially, may resemble a septum, bronchi and blood vessels not being visible. Secondary lobules are usually continuous with each other, being interrupted only by the large structures which traverse the pulmonary tissue. From the sheaths around bronchi and blood vessels small projections of areolar tissue often pass into neighbouring lung, in size resembling the smaller septa which arise from pleura.

Not only does the subpleural region show a different arrangement from that in the deeper part of the lung, but there is also considerable variation in regional distribution of septa, which to some extent can be related to the lung's contour. The most striking illustration of this variation is the sparsity of septa over the large expanse of the costal aspect of the lower lobe and their frequency at the anterior sharp edge of the upper lobe, where they divide the lung into relatively small and well-defined compartments.

\section{Distribution in Relation to Contour}

The distribution of septa in the subpleural region of the lung varies with the particular 


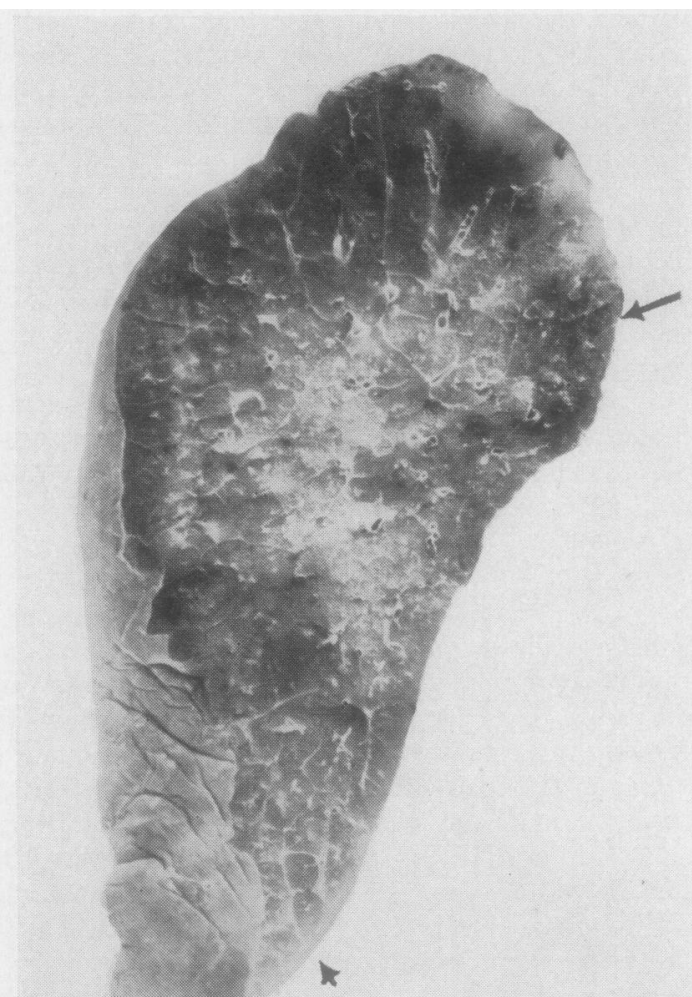

Fig. 1.-Left upper lobe (the lingula lies to the left) of an adult lung showing regional variation in distribution of septa. Between the arrows, on the fissural surface only one septum is present, while to the left along the anterior edge they are frequent.

surface, edge, or margin. Away from its margins and edges the costal surface of the lung has few septa, large expanses being comparatively free. Where they are present, however, they are often attached to the pleura over a distance of several centimetres.

Sharp Edge, Including Angle Where Its Direction Changes.-Towards an edge of the lung the number of septa generally increases so that the respiratory tissue may be divided into compartments rather like a honeycomb save that the walls of the cells are incomplete. At a sharp edge or angle the units are triangular in crosssection, with only a few primary lobules of respiratory tissue at their apices and with pleura forming a boundary on two sides; here septa are attached to the pleura on both sides and are themselves roughly triangular. This is the arrangement, for example, over the lower part of the anterior edge of the upper lobe and the costophrenic edge of the lower lobe, in both of which sites septa are usually found at quite regular $\bar{C}$ intervals of 1 to $2 \mathrm{~cm}$., so that a cut near and parallel to either of these edges will cut across a $\frac{\bar{\Phi}}{\widehat{D}}$ considerable number of septa.

Where the edge changes direction at the point or angle of a lobe, septa passing in at approximately right angles from both pleural surfaces will come very close together and may $\vec{\omega}$ even join (Fig. 1). The tip of the lingula is an 0 example of this, and serial sections from it were $\overrightarrow{\vec{x}}$ used to reconstruct the arrangement of septa $\vec{A}$ shown in Fig. 4.

The Blunt Margin. - The postero-medial $\vec{\omega}$ margin of the lung is not sharp like the anterior $\infty$

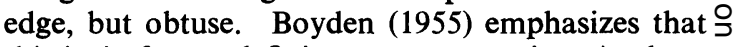
this is, in fact, a definite crest or margin. As there are a large number of septa it resembles the sharp $\subseteq$ edge, but the compartments in cross-section are $\overparen{\Phi}$ not wedge-shaped units but are more oval or $\vec{\varphi}$ cylindrical because of the curve of the lung surface.

\section{Regional Arrangement of Septa}

THE APEX.-The apical part of the lung is usually well subdivided by septa, but not so $\frac{\mathscr{Q}}{\not}$ plentifully as the lingula. Horizontal slices often $\cong$ show a septum of considerable length passing $\overrightarrow{\vec{O}}$ caudally into the lung in an antero-posterior 3 direction, with several small ones approaching it from the lateral aspects.

Fissures.-Save where they approach the angles of the lobe, the fissural surfaces of the lung are usually entirely free of septa, although an $\times$ occasional one may be seen.

Diaphragmatic Surface.-From the diaphragmatic surface a number of septa arise, particularly at its edge; the costophrenic edge is angled ${ }_{\circ}$ acutely and resembles the sharp anterior margin? of the upper lobe in that it is only about oneo lobule thick. Over the central, flatter, part of the diaphragm septa are less frequent than at its rim. If the lung is sliced parallel to the diaphragmaticn surface several septa may be seen arising from N the postero-medial angle and radiating into the ${ }_{\sigma}^{\omega}$ lung to a depth of perhaps $3 \mathrm{~cm}$.

Hilum.-At the hilum septa may meet, within a short distance, the areolar tissue surrounding the blood vessels and bronchi, so that in this region also the subdivision into units is often ${ }_{0}^{-}$ nearly complete.

\section{Numerical Counts of SePta}

Five lungs were sliced vertically at centimetre intervals and the septa in each slice counted. Forô 

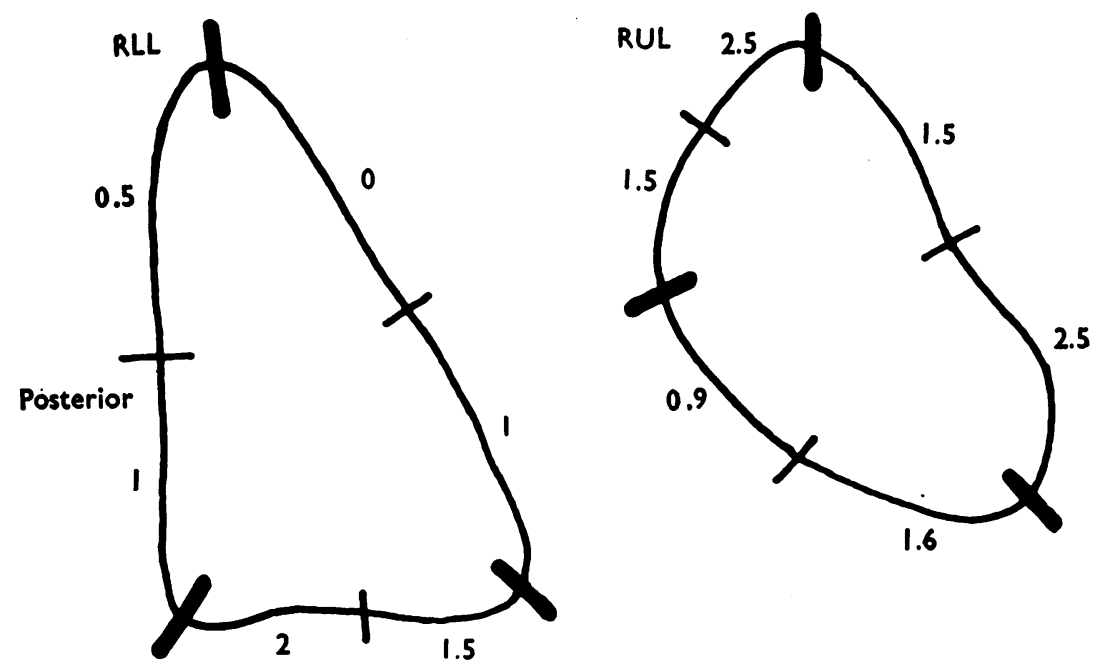

RML
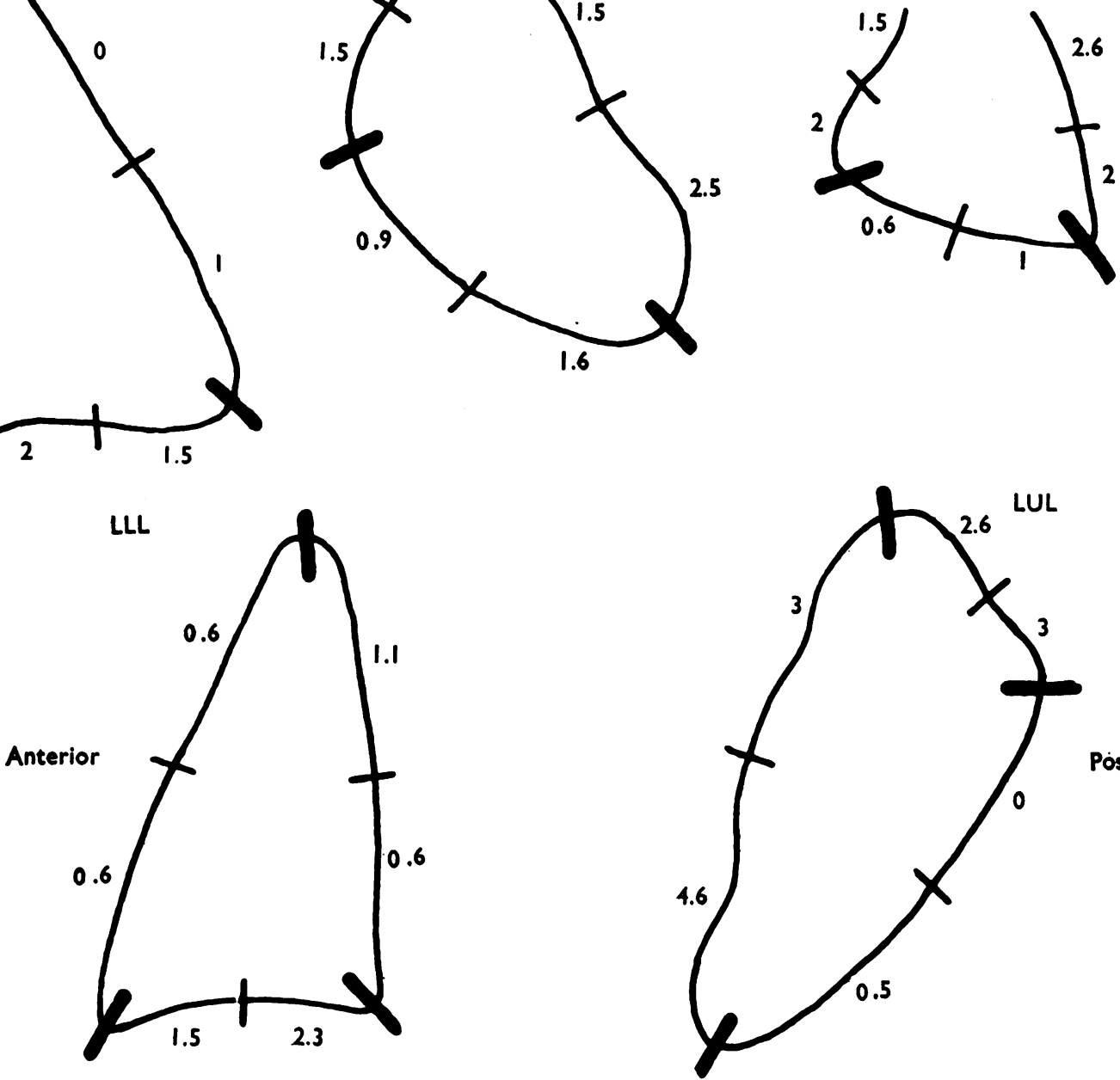

Anterior $\vec{A}$

Fig. 2.-A vertical cross-section of each lobe, each of the three sides of a lobe being divided in two. The number of septa in each of these six regions of each lobe were counted separately in successive vertical sections of an adult lung, and from these results the average count made in each region was estimated.

this purpose, as with the foetal lung, each side of the lobe was divided into two approximately equal parts, so that it was possible to gain some idea not only of the total number at any level but also of their distribution at the circumference of each slice. As a lobe is roughly triangular in section, six counts were thus made at each level. The average for each edge was established, all lungs giving similar counts. The results from each lobe of a particular subject are shown in diagrammatic form in Fig. 2. These figures indicate the frequency of the septa and emphasize the variation in regional distribution described above.

\section{Communications Between Neighbouring LOBULES}

The degree of continuity between respiratory tissue varies considerably in different parts of the lung. For example, near the costal surface of the lower lobe, where septa are few, alveoli are freely continuous, the lung being punctuated only by bronchi and pulmonary artery and pulmonary vein. Closer to the hilum there is less alveolar tissue and the bronchial and vascular structures are relatively much larger. Where septa are numerous and subdivide the lung more closely the respiratory tissue of adjacent inter-septal 


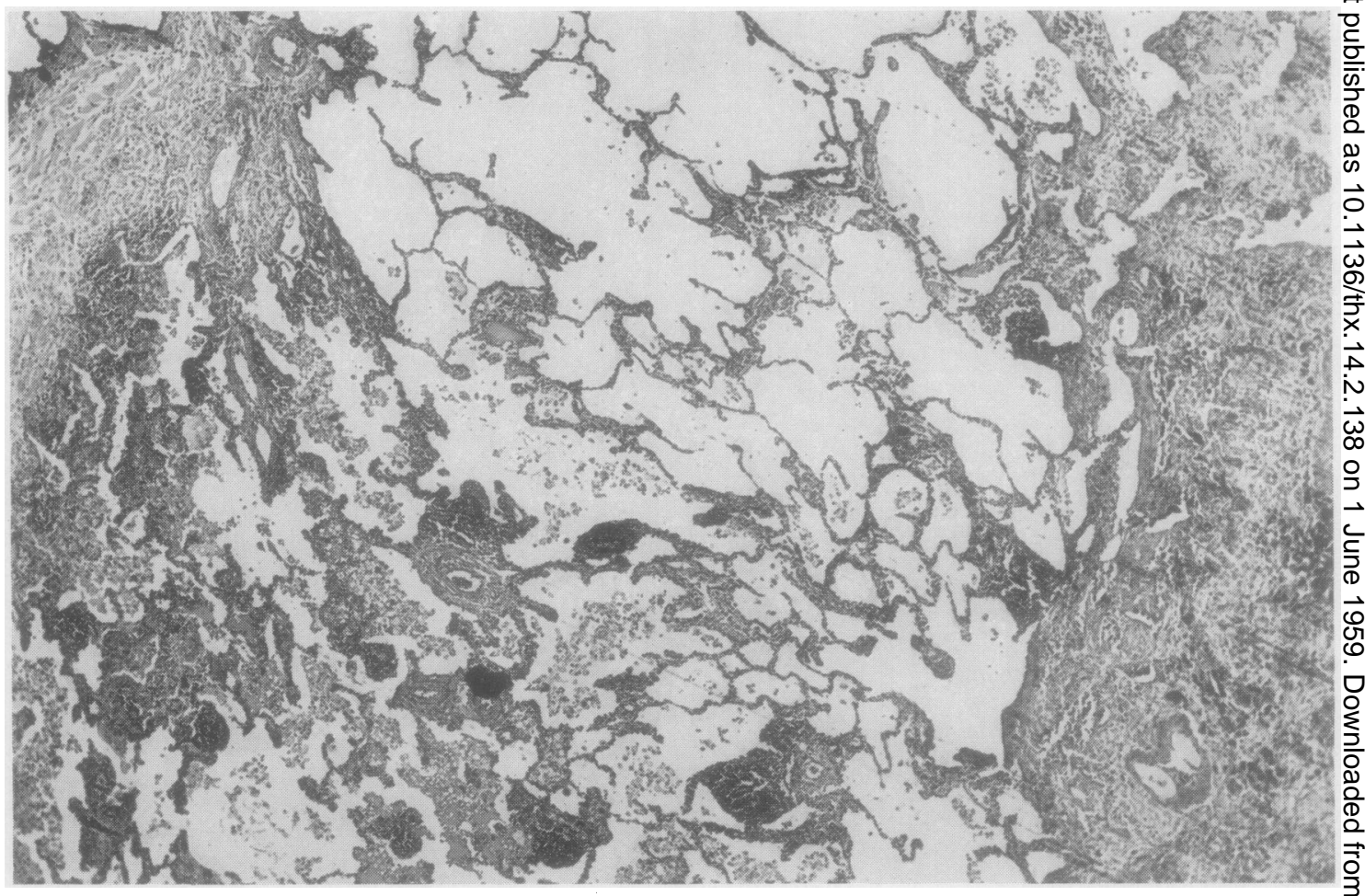

FIG. 3.-Section of endogenous lipoid pneumonia distal to a carcinoma blocking a segmental bronchus. Macroscopically the zone of consolidation had a linear edge, but histologically the change increases gradually across a fenestration in two thickened connective tissue septa to the right and left of the figure from empty alveoli at the top through alveoli containing many lipoid-filled phagocytes in the lower part to a zone of complete consolidation not included in this section. $(\times 15$.)

compartments is still continuous, particularly on their central side. In addition, the septa are not always complete, fenestrations being present which allow inter-septal compartments to communicate laterally through a group of alveoli (Fig. 3).

\section{Attachment of SePta}

Within such relatively well-defined units as those that have been described along the anterior edge of the lung, the smaller septa which sometimes arise from the pleura may pass obliquely through the lobule to become attached either to the broncho-vascular bundle or to other septa. Several of these also are illustrated in Fig. 4, where a minor septum is seen to curve in from the pleura on one side, becoming continuous both with the main one, and with another minor septum, arising from pleura on the other side and curving across to the main septum. For a short distance this septum is fused with the areolar tissue around the broncho-pulmonary bundle, forming as it were a sling or tie between the pleural septum and supplying bronchiole. These small septa may attach to the point of division of a terminal bronchiole or to even more proximal points of branching of the bronchial tree.

\section{DISCUSSION}

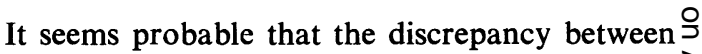
the findings described in this paper and the long- $\frac{D}{0}$ accepted idea that the human lung is subdivided into secondary lobules by connective tissue septa $N$ is due partly to incomplete examination and partly to the prominence of the septa in pathological and embryological material which $\omega$ has particularly been examined. There are also several features of normal adult lung architecture ${ }^{\circ}$ which give the impression that there is subdivision ${ }_{\mathscr{D}}$ by connective tissue septa. Cut surface of lung includes scattered bronchi each running with $a_{0}^{0}$ pulmonary artery and, lying approximately

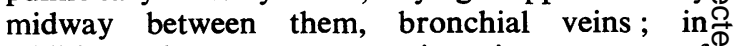
addition, there are connective tissue septa of $\varrho$ varying degrees of completeness. Furthermore,, where there is an accumulation of particulate 8 matter, such as coal dust, at the periphery of a을 


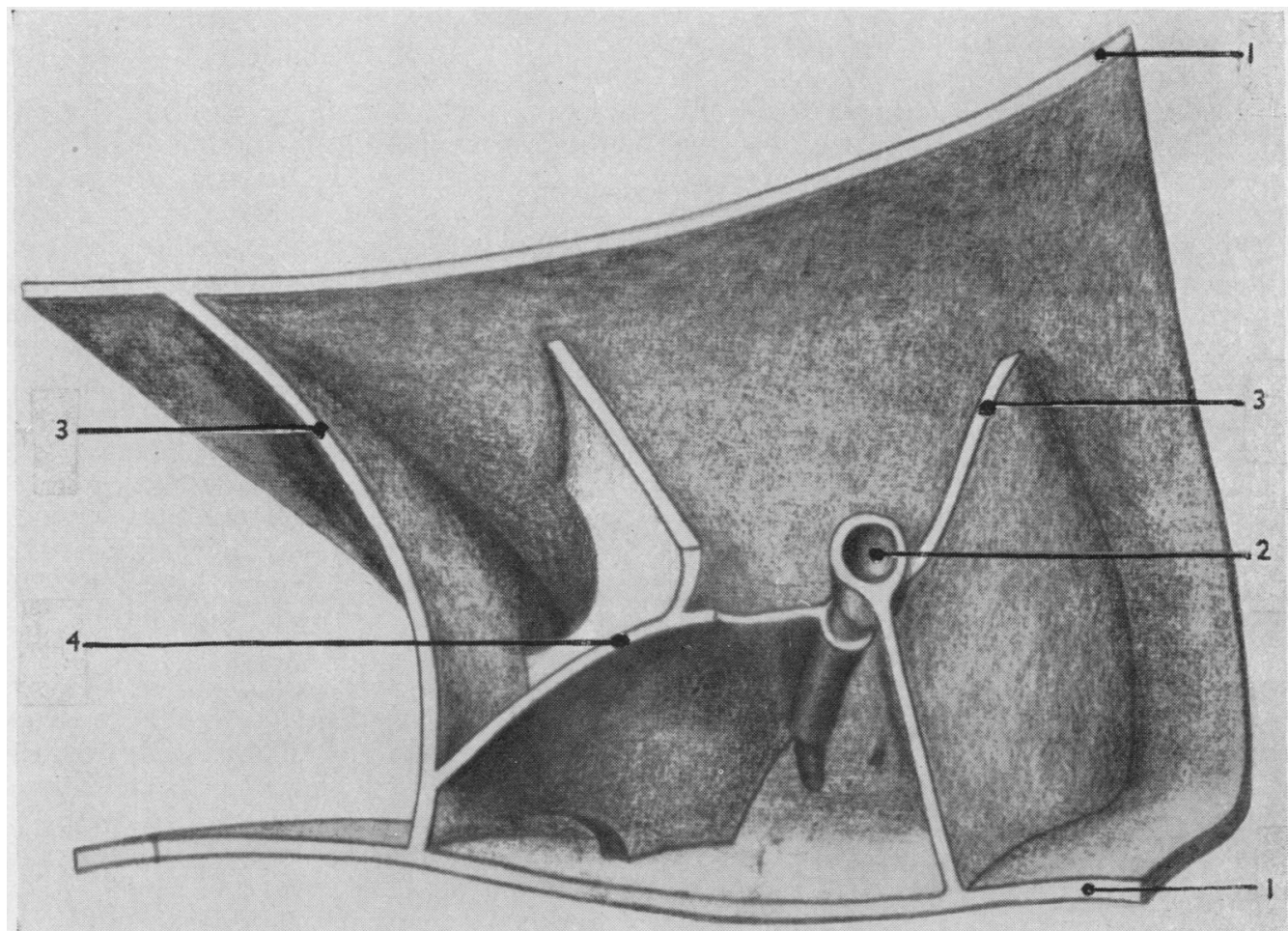

Fig. 4.-Reconstruction of the arrangement of the connective tissue septa in a volume of lung about $1 \mathrm{c.cm}$. in volume at the tip of the lingula. The cut edges of pleura are shown at the top and bottom of the drawing (1), and at (2) a bronchovascular bundle curves into the compartment bounded by the connective tissue septa (3) shown at the left and right. The latter attaches to the bronchiole (2), as does also the septum (4) in the middle, which curves from both pleural margins and attaches also to the larger septum on the left and to the bronchiole.

lobule, the edge of the lobule will still be the limit of the alveoli supplied by a given bronchiole, whether or not it is bounded by connective tissue, so that its structural limits may be seen etched by the distribution of the particulate matter. In embryological material the septa lie closer both to each other and to deeper structures, post-natal growth of the respiratory part of the lung resulting in separation. In disease the septa are often thickened and prominent, and, if the lung is collapsed, those of the subpleural zone lie nearer to the connective tissue sheaths around the bronchi and blood vessels deeper in the lung, which at the same time become closer to each other. The incompleteness of the septa is not then so evident. In chronic collapse, for example, the lung may appear as a mosaic of units of airless lung delineated by white lines representing septa or large veins and their sheaths.

The incompleteness of the septa is fundamental to the operation of collateral air drift in human lung; where septa are concentrated collateral ventilation is impeded. By contrast, in the lung of the cow each lobule is completely encapsulated by areolar tissue and there are no alveoli. serving as interlobular bridges, which arrangement is reflected in the observation by Van Allen and Lindskog (1930) that the calf was the only animal they studied in which collateral ventilation could not be demonstrated. Furthermore, the cow is especially prone to interstitial emphysema, in which septa are seen on the surface of the lung delineated by air bubbles resembling a string of beads. On the cut surface the appearance may be similar or there may be so much air within the septa that they are more like air cysts compressing intervening tissue. This is presumably because, when air enters into the septa, perhaps from ruptured alveoli, it can freely spread throughout a lobe along the connective tissue planes, the lobular pattern being then indicated, both on the cut surface and pleura, by the string of air bubbles.

Because this incompleteness is, in man, essential for collateral air drift, the variation in regional distribution means that there are parts of the 
lung where air drift is less effective. The "protective" action of this cross ventilation can best be illustrated by reference to bronchial obstruction at lobar and segmental level; for example, as the right middle lobe has only two segments, each is continuous with only one other, unlike the middle basal segment which is continuous with three or four others and has only two surfaces "isolated" by pleura. The incidence of collapse in the middle lobe is high. This is probably attributable to hilar anatomy (Brock, 1950), the disposition of the middle lobe bronchus and the lymph nodes near the hilum predisposing to obstruction. The frequent association of airlessness with such obstruction reflects the greater pleural isolation of this lobe. Obstruction to two segments of either upper or lower lobe is not often accompanied by complete collapse ; in fact, true segmental collapse is rare. Like the segments of the right middle lobe, the inferior segment of the lingula is continuous with only one surface of one other segment and airlessness, particularly at its tip, is frequent in diseased lungs. Here the high concentration of septa combines with isolation of the segment in predisposing to collapse.

Certain morphological features of diseased lung can probably be explained only by the unequal operation of collateral air drift. In bronchiectasis, the distal part of a diseased segment is often collapsed while the proximal level is still aerated, although in a bronchogram the bronchi are equally affected throughout the segment. This suggests that throughout the segment the bronchi are obliterated, but that the proximal part of the segment has been kept aerated by collateral ventilation from neighbouring normal lung. Churchill (1951) has emphasized the importance of this phenomenon in maintaining what he called the "space occupying" function of lung.

The irregular operation of collateral ventilation in the subpleural zone is illustrated by the distribution of the minute foci of fibrosis and collapse seen in chronic bronchitis (Reid, 1956). These are about twice as frequent immediately under the pleura as in the deeper part of the lung.

Collateral ventilation has above been invoked to account for certain patterns of air-absorption collapse ; it would seem also that it contributes to the development of bullae in emphysema. The structural isolation which impedes the entry of air may equally hinder its escape. Although emphysema occurs throughout the lung, the local overdistension which gives rise to bullae occurs subpleurally, and the characteristic fringe of bullae along the anterior edge of the lung, at the apex, and on the diaphragmatic surface suggests that the development of bullae is the consequence $\frac{\bar{T}}{\bar{D}}$

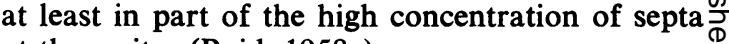
at these sites (Reid, 1958a).

In the child the septa are closer together as well as to the bronchial and vascular bundles, and $\vec{\circ}$ therefore offer more hindrance to collateral air drift. The lung increases in volume $\vec{\omega}$ approximately seventy-fold from baby to adult. Post-natal growth occurs in particular at two $\vec{x}$ points (Broman, 1923 ; Willson, 1928). One is in $\vec{A}$ the alveoli where new alveoli bud, and the otheriv is in the terminal bronchiole, from the wall of $\vec{\omega}$ which muscle and epithelium grow down to ${ }^{\infty}$ convert alveolar ducts to respiratory bronchioles $\triangle$ (Bremer, 1935). With development, therefore, the pleura lies further away from the nearest bronchioles and the septa from the bronchial or $ळ$ vascular bundles; and any fenestrations in the $\vec{c}$ septa probably increase in diameter. This suggests that collateral ventilation operates to a less degree in the infant than in the adult, bronchiolaro obstruction being more often followed by collapse. This is, therefore, one factor in theo greater clinical significance of acute bronchiolitis? in the baby and child.

In certain normal chest radiographs a few $\overrightarrow{\overrightarrow{0}}$ horizontal line shadows, $1-2 \mathrm{~cm}$. in length, may be visible above the costophrenic recess (Simon, 1956). In disease these may be thickened and are then seen more obviously and frequently, as in the lines described by Shanks and Kerley (1951). These lines may represent either septa or alveoli based on them as, for example, when 3 haemosiderin is lodged in adjoining alveolìn (Fleischner and Reiner, 1954). The transients lines often associated with acute ventricular failure may represent oedema of the septum or dilatation of a lymphatic within it.

The variation in the distribution of the septa and the fact that they are not complete haveos further anatomical and functional implications both for normal and for diseased lung. Fonv instance, the long-accepted definition of the $e_{\sigma}^{\omega}$ secondary lobule by reference to the septa is no longer satisfactory and an alternative one, basede on the pattern of branching of the bronchial tree has recently been suggested (Reid and Simon;1958 ; Reid, 1958b).

\section{SUMMARY}

The connective tissue septa in the human lung are irregular in their regional distribution. The deeper parts of the lung are largely free, the septa 
being mostly concentrated in the subpleural zone. Generally speaking, septa are frequent over the sharp edges and angles of the lung (such as the anterior edge of the upper and middle lobes, the costophrenic edge of the lower lobes, and the costovertebral margins), relatively scarce over the lateral or costal aspects, and absent over the fissural surfaces.

The incompleteness of septa is essential to the operation of collateral ventilation, a phenomenon whose effectiveness is relatively impaired in regions where septa are numerous and which influences the functioning of the lung and its appearance in disease.

My thanks are due to Dr. Donald Teare, St. George's Hospital Medical School, for providing some of the normal adult lungs used in this study; and to Mrs. U. G. Bucher for drawing Fig. 4.

REFERENCES

Birnbaum, G. L. (1954). Anatomy of the Bronchovascular System. Year Book Publishers, Chicago.

Boyden, E. A. (1955). Segmental Anatomy of the Lungs. McGraw-Hill, New York.
Bremer, J. L. (1935). Postnatal Development of Alveoli in the Mammalian Lung in Relation to the Problem of the Alveolar Phagocyte. Contrib. Embryol. Carneg. Instn, 25, No. 147.

Brock, R. C. (1950). Thorax, 5, 5 .

Broman, I. (1923). Anat. Anzeiger, 57, Ergänzungsheft, p. 83.

Churchill, E. D. (1951). Obliterative Bronchitis and Bronchiectasis. The Alex Simpson Smith Lecture. Institute of Child Health, University of London.

Cunningham, R.S. (1916). On the Development of the Lymphatics of the Lungs in the Embryo Pig, Contrib. Embryol. Carneg. Instn, 4, No. 12

Felix, W. (1928). “Anatomie der Lungen," in Chirurgie der Brustorgane, by F. Sauerbruch, p. 145, 3rd ed. Springer, Berlin.

Fischer, F. K. (1953). In Roentgen-Diagnostics, Vol. III, p. 2032, by Schinz, H. R., Baensch, W. E., Friedl, E., and Uehlinger, E. 1 st American edition. William Heinemann, London.

Fleischner, F. G., and Reiner, L. (1954). New Engl.J. Med., $250,900$.

Flint, J. M. (1906). Amer. J. Anat., 6, 1.

Laguesse, E., and d'Hardivillier, A. (1897). Bibliogr. Anat., 1897-8, $6,125$.

Loosli, C. G. and Pot:er, E. L. (1951). Anat. Rec., 109, 320.

Miller, W. S. (1947). The Lung, 2nd ed. Charles C. Thomas, Springfield, Ill.

Reid, L. (1956). Proc. roy. Soc. Med., 49, 767.

(1958a). Pathology of Chronic Bronchitis. In Recent Trends in Chronic Bronchitis, ed. N. C. Oswald, p. 26. Lloyd-Luke, London.

(1958b). Thorax, 13, 110

- and Rubino, M. (1959). Ibid., 14, 3.

and Simon, (1958). Ibid, $13,103$.

Shanks, S. C., and Kerley, P. J. (1951). A Text Book of X-Ray Diagnosis, 2nd ed., Vol. 2 , p. 404 . Lewis, London.

Simon, G. (1956). Principles of Chest X-Ray Diagnosis. Butterworth. London.

Van Allen, C. M., and Jung, T. S. (1931). J. thorac. Surg., 1, 3.

and Lindskog, G. E. (1930). Arch. Surg. (Chicago), 21, 1195.

Willson, H. G. (1928). Amer. J. Anat., 41, 97. 